\title{
Is distyly in subtropical Psychotria brachyceras (Rubiaceae) similar to the general trends observed for the genus?
}

\author{
Renata Trevizan ${ }^{1^{*}}$ (D), Raquel Lüdtke ${ }^{2}$ (D), João Custódio Fernandes Cardoso ${ }^{3}$ (D), Paulo Eugenio Oliveira ${ }^{4}$ (i) \\ and Nathália Susin Streher ${ }^{1}$ (i)
}

Received: February 20, 2020

Accepted: March 16, 2021

\begin{abstract}
Distyly is a floral polymorphism that promotes cross-pollination through precise pollination. Psychotria is a mostly tropical genus of distylous Rubiaceae. Although widely studied in Brazil, some regions/species are still poorly explored, which hinders the understanding of distyly system along a greater geographical range. Here, we studied a subtropical population of Psychotria brachyceras in southern Brazil. For this, we characterized morphs occurrence, reciprocity of sexual structures, mating and incompatibility systems. In addition, we compared the reciprocity values from other species of the genus based on values gathered from literature to understand how the population behaves. The population showed equal proportions of thrum (short stigma/high anthers) and pin (high stigma/short anthers) morphs. Reciprocity was higher than the average for the genus and inaccuracy values between sexual organs were evenly distributed between the organ types, indicating a trend to typical distyly. Higher fruit set rates in intermorph and open pollination treatments and pollen tube growth observations confirmed that the population has a functional heteromorphic incompatibility system. Psychotria brachyceras showed no signs of distinct traits to typical distylous populations, which seems to ensure reproductive success and distyly maintenance.
\end{abstract}

Keywords: heterostyly, pollen tube growth, pollination, reproductive biology, self-incompatibility

\section{Introduction}

Distyly is the most widespread form of heterostyly and seems to have evolved independently in 26 angiosperm families (Naiki 2012). Theoretically, the corresponding position of anthers and stigmas in two different morphs assures reciprocal herkogamy and has been considered a mechanism that promotes cross-pollination (Darwin 1877). Distyly is frequently associated with a heteromorphic sporophytic self-incompatibility system that further prevents self and intramorph mating and ancillary characteristics, e.g., pollen size, pollen number and size of stigmatic papillae (Ganders 1979; Dulberger 1992; Barrett \& Shore 2008; Costa et al. 2017). These characteristics combined are expected to result in a 1:1 morph ratio in distylous populations (i.e., isoplethy; Ganders 1979). However, the polymorphism features can be unstable in some distylous groups (Jiang et al. 2018). Anomalies in these features may indicate disruption of distyly function and have been associated with physiological or ecological factors, such as changes to population morph structure and floral morphology, variation in incompatibility system and breakdown of the

1 Programa de Pós-Graduação em Biologia Vegetal, Universidade Estadual de Campinas, 13083-970, Campinas, SP, Brazil

2 Instituto de Biologia, Universidade Federal de Pelotas, 96010-900, Pelotas, RS, Brazil

3 Instituto de Ciências da Natureza, Universidade Federal de Alfenas, Alfenas, MG, Brazil

4 Instituto de Biologia, Universidade Federal de Uberlândia, 38405-320, Uberlândia, MG, Brazil

*Corresponding author: renatattelles@gmail.com 
polymorphism to homostyly (flowers with stigmas and anthers at the same height) or a monomorphic condition (populations with only one thrum or pin morph; Sakai \& Wright 2008; Ferrero et al. 2012; Zhou et al. 2017). Distylous species require obligate and precise pollination service to assure the function and maintenance of the polymorphism. This occurs because pollen needs to be placed in specific but different parts of pollinator's body to optimize legitimate pollen transfer between reciprocal morphs (disassortative pollination) and hence reduce pollen wastage (Lloyd \& Webb 1992; Keller et al. 2014; Barrett 2019). Deviations from reciprocal positions of the anthers and stigmas between different morphs may reduce pollination efficiency due to asymmetric pollen flow. This may be related to a decrease in intermorph and an increase in self- and intramorph pollen deposition which in turn results in little or no seed set (Keller et al. 2014; Zhou et al. 2015; Brys \& Jacquemyn 2019). Therefore, morphological (i.e., intermorph reciprocity) and physiological components minimize self- and intramorph pollination, enhance male and female reproductive fitness, and ensure greater reproductive outcrossing success in distylous populations (Dulberger 1992; Barrett 2002; Barrett \& Shore 2008; Keller et al. 2014).

Considering the occurrence in angiosperms, Rubiaceae is the family containing the largest number of species with distyly (Naiki 2012). Within this family, Psychotria is the largest genus, comprising more than 1,800 species, in which distyly is rather common (Davis et al. 2009). This makes Rubiaceae and, more specifically, the genus Psychotria, suitable to study the evolution/breakdown of heterostyly system. Psychotria is distributed mainly in tropical regions (Naiki 2012), where these plants are important elements of forests, and it is thought that distyly may have had a role in the diversification of this species-rich genus (Ferrero et al. 2012). Nevertheless, Psychotria populations occurring outside the tropics are poorly studied. One interesting case is Psychotria rubra in the islands of Japan (Watanabe et al. 2013). Despite the morphological dimorphism between pin (high stigma/short anthers) and thrum (short stigma/high anthers) morphs in this species, the anthers of the former lack pollen and are specialized in setting fruits. On the other hand, thrum morphs never set fruits and are specialized in pollen exportation. This leads to a functional dioecy with pin individuals playing the role of females whereas thrums the role of males. Deviations from reciprocal arrangement between stigma and anther heights of morphs have also been reported in other subtropical populations (Castro \& Araújo 2004; Watanabe et al. 2014). These findings raise the question of whether anomalies and even the breakdown of distyly in Psychotria species might be more common outside the tropics in general. However, we still lack basic reproductive knowledge on most southern subtropical populations to allow comparisons and possible insights about geographic variations and evolution of distyly within Psychotria.

The genus Psychotria in Brazil is widely studied (e.g., Coelho \& Barbosa 2004; Teixeira \& Machado 2004; Lopes \& Buzato 2005; Consolaro et al. 2011; Rodrigues \& Consolaro 2013; Matias et al. 2016; Sá et al. 2016), however, none populations from the south of Brazil has had its reproductive features investigated so far, creating a gap in the knowledge of the group. Since distyly relies on pollinator's service for cross-fertilization (Barrett 2019), describing how subtropical distylous species function and comparing them with tropical distylous ones might help to understand whether patterns change depending on the geographic location of populations. Psychotria brachyceras (Rubiaceae) is an understory shrub endemic to Brazil, distributed along southeast and south regions, encompassing tropical and subtropical areas (Taylor 1996). Here, we investigated distyly features of one P. brachyceras population in southern Brazil, particularly aiming to define (i) the proportion of morphs in the population; (ii) the floral morphology; (iii) the reciprocity of reproductive structures between morphs; (iv) the mating system and (v) pollen tube growth after manual self-pollination and intermorph cross-pollination. In addition, (vi) we gather the available data in the literature on reciprocity (i.e., means and standard deviations of anthers' and stigmas' heights of each morph) of other distylous populations of Psychotria check whether P. brachyceras shows similar patterns. With this, we can evaluate the distyly status of this population.

\section{Materials and methods}

\section{Study area}

The study was carried out in the Horto Botânico Irmão Teodoro Luís ( $31^{\circ} 48^{\prime} 55^{\prime \prime} \mathrm{S}, 52^{\circ} 25^{\prime} 55^{\prime \prime} \mathrm{W}$ ), a preserved area of 23 ha in Capão do Leão municipality, Rio Grande do Sul state, southern Brazil. The studied population is located in a forest fragment and is predominant in the understory layer. The area is located in the Pampa biome, with Cfa climate (subtropical with hot summer) according to Köppen climate classification, with mean monthly temperature of $17.3^{\circ} \mathrm{C}$ and a mean annual rainfall of $1461 \mathrm{~mm}$ (Alvares et al. 2013).

\section{Studied species}

Psychotria brachyceras Müll.Arg. has small white flowers, with tubular corolla and a yellow ring surrounding its opening (Fig. 1). Flowers are arranged in cymose inflorescences and present two ovules per flower. Populations of the species typically have thrum and pin floral morphs (Fig. 1). In the studied population, flowers are visited by bees, butterflies, and hummingbirds (R Trevizan, personal observation). 


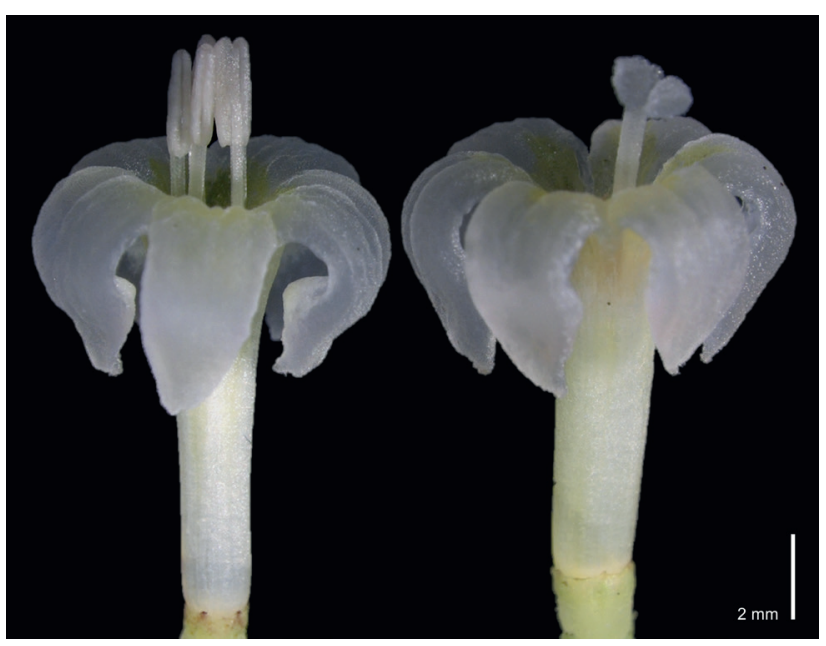

Figure 1. Flowers of Psychotria brachyceras (Rubiaceae) showing the detail of thrum (left) and pin (right) morphs.

\section{Morphs ratio}

Population morph ratio was studied by surveying plants along three trails at the study site. On each trail, every two meters we entered two meters into the forest, both to the left and right sides of the trail (covering a total of 300 $\mathrm{m})$. We identified and counted the plants in two flowering periods, December 2015, and December 2016.

\section{Floral morphology}

We selected 10 individuals of each morph for morphological measurements. From each individual, we collected one to three flowers, totaling 36 thrum and 38 pin flowers. The measurements taken were: corolla length and width, stigmas' and anthers' lengths and heights. Flowers were measured when still fresh using a scale under a stereo microscope (Discovery V20 - Zeiss ${ }^{\circ}$ ).

\section{Reciprocity between morphs}

We used the adaptive inaccuracy to measure reciprocity between morphs (Armbruster et al. 2017). According to this index, the greater the values of inaccuracy, the lower the reciprocity. Inaccuracy was calculated based on populations' means and variances of anthers' and stigmas' heights of each morph. We then partitioned the independent contributions of imprecision (variances on stigmas anthers per morph) and maladaptive bias (departure from optimum reciprocity of high and low organs).

In addition, we also reviewed the literature and gathered the information about the reciprocity in populations of the genus Psychotria. We conducted the review using the Google Scholar (https://scholar.google.com.br/) and the CAPES Scientific Journals gateway (http://www.periodicos.capes. gov.br/), using the key words Psychotria, heterostyly and/or distyly. In addition to papers and thesis, we also incorporated non-published personal data. The information collected included taxonomic information (species of Psychotria) and the morphometry measurements as the means and standard deviation (SD) of stigma and anther heights of pin and thrum morphs.

We then compared whether the inaccuracy values of $P$. brachyceras were larger than those of the genus by investigating if the observed values fell outside the $95 \%$ confidence interval (CI). We calculated CIs using the R-package Rmisc version 1.5 (Hope 2013) and applied logarithmic (+1) transformation to improve data normality. In order to generate equivalence among the distinct populations/species, we mean ${ }^{2}$-standardized the inaccuracies by the average organ height (i.e., dividing inaccuracies by the means, raising the result to the power of two and them multiplying by 100), creating proportional values that allow comparison across populations and species (following Armbruster et al. 2017 and Trevizan et al. 2021).

\section{Mating system}

The mating system (sensu Cardoso et al. 2018) treatments were carried out during November and December 2015. We selected 39 individuals of each morph and bagged buds with voile mesh 'bags' to avoid any contact with floral visitors. After bud opening, the following hand pollination treatments were performed: (1) spontaneous self-pollination - floral buds were only isolated without further manipulation (thrum = 34 flowers; pin = 30 flowers); (2) manual self-pollination - pollen transfer within-flower (thrum = 16; pin =19); (3) intramorph cross-pollination - pollen transfer between flowers of different individuals from the same morph (thrum = 25; pin = 20); (4) intermorph cross-pollination - pollen transfer between flowers of different individuals and morphs (thrum recipient $\mathrm{x}$ pin donor $=16$; pin recipient $\mathrm{x}$ thrum donor =19); (5) agamospermy - buds were emasculated and bagged (thrum = 28; pin = 30); and (6) open pollination - flowers were allowed to be accessed by visitors freely (thrum = 39; pin = 39) (adapted from Dafni 1992). We used one flower per treatment per individual. Treatments were monitored periodically to check whether they had formed fruits or not.

\section{Pollen tube growth}

To check for self-incompatibility and site of pollen tube arresting along the pistil, we observed pollen tube growth after repeating the manual self-pollination and the intermorph cross-pollination treatments described previously. For the manual self-pollination, we selfpollinated 17 flowers of each morph (17 thrum; 17 pin). For the intermorph cross-pollination treatments, we transferred pin pollen to 17 thrum flowers (thrum recipient $\mathrm{x}$ pin donor), and thrum pollen to 18 pin flowers (pin recipient $x$ thrum donor). Pistils were collected and fixed in $50 \%$ FAA (Formalin-Acetic acid-Alcohol; Johansen 1940) after 8 hours (self: 9 thrum and 11 pin; cross: 8 thrum recipient $\mathrm{x}$ pin donor and 8 pin recipient $\mathrm{x}$ thrum donor) and 16 
hours (self: 8 thrum and 6 pin; cross: 9 thrum recipient $x$ pin donor and 10 pin recipient $x$ thrum donor) of pollen transfer. Pistils were softened in a $\mathrm{NaOH} 9 \mathrm{~N}$ solution and put in a stove at $60^{\circ} \mathrm{C}$ for $15 \mathrm{~min}$, washed in distilled water and stained with aniline blue (adapted from Martin 1959). Under a fluorescence microscope, we observed whether pollen grains germinated in the stigma and, if so, whether pollen tubes were present at the base of the style. We did not observe the ovary region because the solution used damaged the tissue (see Castro \& Araujo 2004).

\section{Statistical analyses}

We assessed whether the population had similar proportions of pin and thrum morphs through chi-square goodness of fit tests, which were performed separately for each year count. We ran a principal component analysis (PCA) on flower morphology variables to attain dimensionality reduction, evaluate associations between measurements, and reveal the most contributive ones. We used the R-package FactoMineR version 1.41 (Husson et al. 2018) and specified a covariance matrix since our variables were on the same scale (mm) (Abdi \& Williams 2010). Morph was treated as a supplementary variable for plotting to show which morphometrics are related to each one (Abdi \& Williams 2010). After finding that the heights of reproductive whorls (stigma and anthers) were the most contributive variables (see Results), we assessed if thrum and pin morphs occupied different regions in a Euclidean space. We did so by running a mixed db-RDA (distance-based Redundancy Analysis; McArdle \& Anderson 2001) using the vegan R-package version 2.5-1 (Oksanen et al. 2018). We set individuals as random effect and performed 10,000 permutations.

Afterwards, we investigated whether each of the morphological traits differed according to morph by running separate LMMs (Linear Mixed-effects Models) using the R-packages lme4 version 1.1-19 (Bates et al. 2018) and lmerTest version 3.0-0 (Kuznetsova et al. 2018). Individual identity was treated as a random effect. We used the natural logarithm of lengths of anthers and stigmas to improve residuals distributions. We applied Bonferroni correction on p-values in order to avoid type I error due to multiple testing (Cabin \& Mitchell 2000) using the p.adjust function in $\mathrm{R}$ software (R Development Core Team 2019) stats package. Whenever a model was found significant, we then calculated the proportion of variance explained by the morph factor through the marginal $R^{2}$ (sensu Nakagawa \& Schielzeth 2013) using the R-package $r 2 \mathrm{glmm}$ version 0.1.2 (Jaeger 2017). We performed exploratory analyses following Zuur et al. (2010) and validated models by inspecting homogeneity of fitted vs. residual values plots, quantile-quantile plots, histograms and Cook's distance (Zuur et al. 2009).

We investigated differences in fruit set according to treatment groups (agamospermy, spontaneous selfpollination, manual self-pollination, intramorph crosspollination, intermorph cross-pollination and open pollination), morph (thrum and pin) and the interaction term by fitting a log-linear model in the R-package MASS version 7.3.53 (Venables \& Ripley 2002). After finding a statistically significant result, we performed post-hoc pairwise tests of independence among the treatment levels with Bonferroni correction using the R-package rcompanion version 2.3.26 (Mangiafico 2020).

We analyzed differences in pollen tube growth by running separated chi-square tests for each time of pollen fixation ( $8 \mathrm{~h}$ and $16 \mathrm{~h}$ ) and site of pollen tube arrestment (stigma or style). After any statistically significant result, we performed post-hoc pairwise tests of independence among the treatment levels with Bonferroni adjusted correction. Analyses were carried out in R statistical environment version 3.6.1 (R Development Core Team 2019).

\section{Results}

\section{Morph ratios}

The proportion of individuals of each morph was similar in 2015 (99 pin vs. 120 thrum; $\chi^{2}=2.01 ; \mathrm{df}=1 ; P=0.16$ ) and 2016 (169 pin vs. 175 thrum; $\chi^{2}=0.10 ; \mathrm{df}=1 ; P=0.75$ ), indicating that the population was isoplethic.

\section{Floral morphology}

The first (63.24\%) and second (25.18\%) PC axes on flower morphometry explained together $88.42 \%$ of data variance (Fig. 2A). Anther and stigma heights were the most contributing variables to the first (respectively 49.89 and $47.20 \%$ ) and second (respectively 31.86 and $47.71 \%$ ) PC axes (see Tab. 1 for details). Based on these two variables, pin and thrum morphs occupied different spaces (db-RDA: pseudo- $\mathrm{F}_{1,71}=120.18, P<0.001 ; \mathrm{R}^{2}=0.63$; Fig. $2 \mathrm{~B}$ ). In this sense, $P$. brachyceras has markedly distinct floral morphs with pins showing high stigmas and short anthers and thrums with short stigmas and high anthers (Fig. 2B, Tab. 2). Stigmas of the pin morph were $30.50 \%$ higher than those of the thrum. On the other hand, anthers of thrum were $29.21 \%$ higher than those of pin. Stigmas were $23.13 \%$ larger on thrum morphs. There were no differences concerning anther length, corolla length and corolla opening (Tab. 2).

Table 1. PCA results of morphological traits in flowers of Psychotria brachyceras (Rubiaceae). Contributions by variable (in $\%)$ for the first two PC axes. In each column, explanations sum $100 \%$.

\begin{tabular}{|c|c|c|}
\hline Variables & PC1 & PC2 \\
\hline Anther height & 49.89 & 31.86 \\
\hline Stigma height & 47.20 & 47.71 \\
\hline Corolla length & 2.71 & 20.22 \\
\hline Stigma length & 0.17 & 0.20 \\
\hline Anther length & 0.03 & $<0.01$ \\
\hline Corolla width & $<0.01$ & 0.01 \\
\hline
\end{tabular}



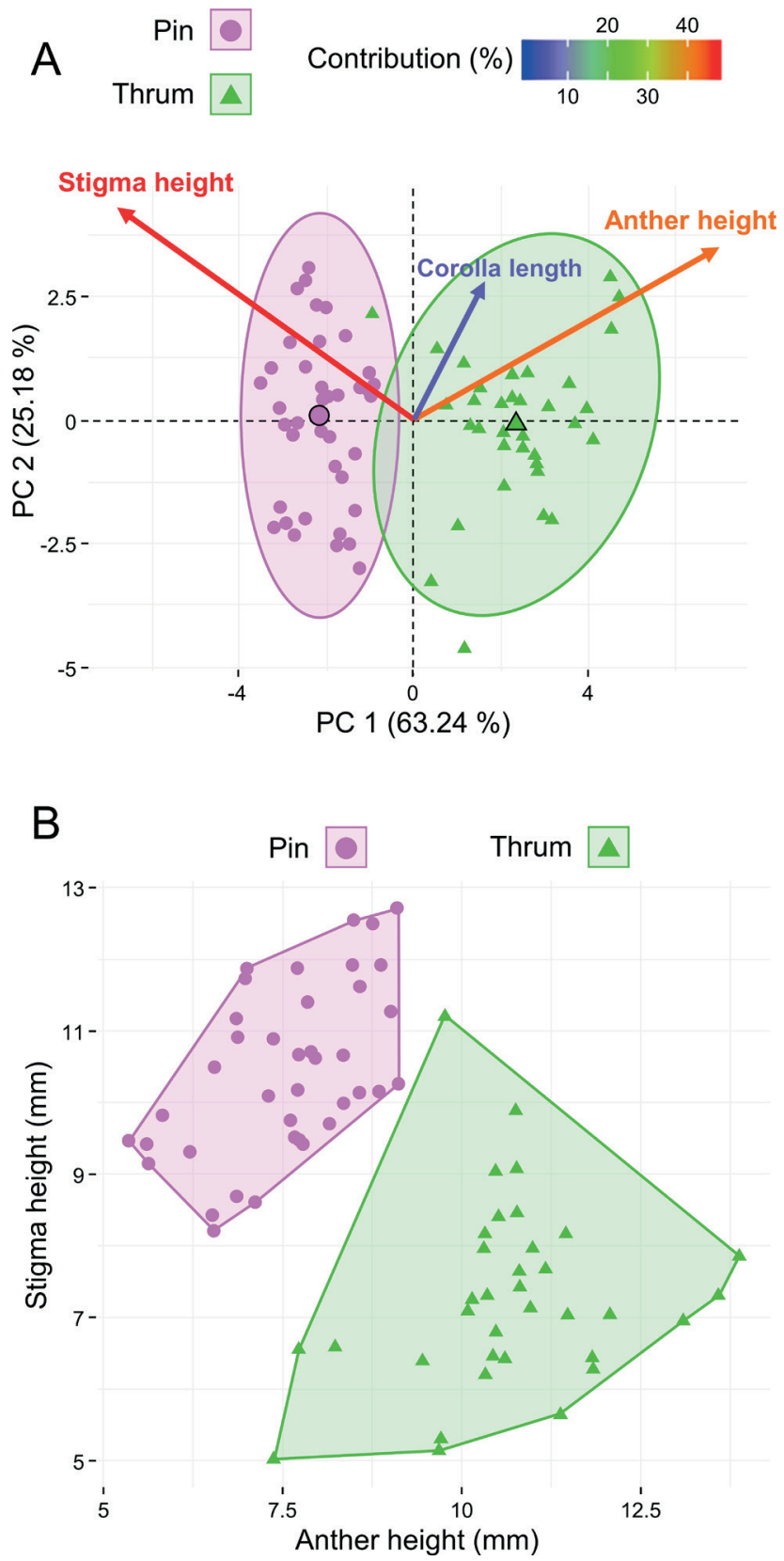

Figure 2. Principal component analysis (PCA) biplot showing contributions of morphological traits. (A) Stigma height, anther height and corolla length according to the two morphs along the first two PCs axes. The other morphometric variables are not included due to their small contributions (see Tab. 1). Contributions are expressed in percentages and ellipses comprise 0.95 CI. (B) Heights of stigmas and anthers according to pin and thrum floral morphs. Polygons indicate the area occupied by each morph by means of the connection of the most extreme points and show the separation between them. Scales of axes have the same aspect ratio.

\section{Reciprocity between morphs}

Psychotria brachyceras had a total inaccuracy of 6.12 (raw inaccuracy). It was evenly distributed between the two organ types, being 3.29 in high organs and 2.83 in low organs.
When values were further decomposed, they were similar across organs per morph (pin anther: 1.08; pin stigma: 1.42; thrum anther: 1.82; thrum stigma: 1.66). Maladaptive bias was 0.05 and 0.08 in high and low organs, respectively.

We recorded 58 populations belonging to 31 species in our literature review (Tab. S1 in supplementary material). Overall, stigmas and anthers variances per morph and the maladaptive bias of high organs were evenly distributed at the genus level, which was not captured for the maladaptive bias of low organs due to the high values (Fig. 3). Low organs inaccuracies were also higher when compared to high organs. Both values of $P$. brachyceras stigma inaccuracies (of thrum and pin) fell much below the confidence limits of the distributions for the genus (Fig. 3; Tab. 3). They were 91 and 59 times smaller than the average values for the genus, respectively. Maladaptive bias of high organs was also much smaller, being $139 \%$ smaller than the mean for the genus. These results contributed most to the smaller values observed for both high organs and total inaccuracies. These were $76 \%$ and $28 \%$ smaller than the mean values, respectively. The anther inaccuracy of pin morph fell only 0.01 above the confidence limits of the genus. Hence, this result may be interpreted with caution because of the small magnitude of the difference, which is only $15 \%$ higher when compared to the genus mean. Anthers of thrum morph, maladaptive bias of low organs and low organs were all within the $\mathrm{CI}$ of the genus.

\section{Mating system}

Concerning the hand pollination treatments conducted to investigate $P$. brachyceras mating system, we found a significant effect of treatment group $\left(\chi^{2}=205.41 ; \mathrm{df}=10 ; P<0.001\right)$, while morph $\left(\chi^{2}=4.73 ; \mathrm{df}=6 ; P=0.58\right)$ and the interaction term (treatment ${ }^{*}$ morph: $\chi^{2}=4.68 ; \mathrm{df}=5 ; P=0.46$ ) were not significant. Fruits were broadly formed in both morphs of the intermorph cross-pollination and open pollination treatments (Tab. 4). The other treatments (agamospermy, intramorph cross-pollination, spontaneous and manual self-pollination) set significantly less fruits, basically showing very low fruit set or the absence of fruits (Tab. 4).

\section{Pollen tube growth}

Pollen germinated in all stigmas regardless of the treatment whereas pollen tubes that grew in styles were treatment-dependent (Fig. 4; Fig. 5). Pollen on stigmas had high rates of germination with no detectable differences in both $8 \mathrm{~h}\left(\chi^{2}=2.34 ; \mathrm{df}=3 ; P=0.51\right.$, Fig. $4 \mathrm{~A}$, Fig. $\left.5 \mathrm{C}, \mathrm{F}\right)$ and $16 \mathrm{~h}\left(\chi^{2}=4.81 ; \mathrm{df}=3 ; P=0.19\right.$, Fig. 4 C, Fig. 5A, B) treatments. However, we found differences in pollen tube growth at the level of the style (Fig. 4B, D). After $8 \mathrm{~h}$ of pollination $\left(\chi^{2}=28.77 ; \mathrm{df}=3 ; P<0.001\right.$, Fig. $\left.4 \mathrm{~B}\right)$, the intermorph cross-pollination treatments (pin recipient $\mathrm{x}$ thrum donor, Fig. 5D, E; thrum recipient x pin donor, Fig. $5 \mathrm{G}, \mathrm{H}$ ) had much higher frequencies of pollen tube growth than both pin and thrum manually self-pollinated pistils. 
Table 2. Floral traits mean \pm SD and comparison tests between thrum and pin morph flowers of Psychotria brachyceras. Significative $\mathrm{p}$-values (Bonferroni corrected) are expressed in bold.

\begin{tabular}{|l|c|c|c|c|c|}
\hline \multirow{2}{*}{ Variables } & \multicolumn{2}{|c|}{ Mean \pm SD } & \multicolumn{3}{c|}{ Statistics } \\
\cline { 2 - 6 } Corolla length & Pin & Thrum & F & 1.0 & P-value \\
\hline Corolla width & $6.75 \pm 0.93$ & $7.25 \pm 0.97$ & 1.57 & 0.81 & - \\
\hline Stigma length & $2.57 \pm 0.49$ & $2.64 \pm 0.57$ & 2.28 & $\mathbf{0 . 0 2}$ & 0.18 \\
\hline Anther length & $1.13 \pm 0.37$ & $1.47 \pm 0.51$ & 9.53 & 1.0 & - \\
\hline Stigma height & $2.53 \pm 0.40$ & $2.43 \pm 0.56$ & 0.62 & $<\mathbf{0 . 0 0 1}$ & 0.62 \\
\hline Anther height & $10.46 \pm 1.19$ & $7.27 \pm 1.29$ & 79.71 & $<\mathbf{0 . 0 0 1}$ & 0.54 \\
\hline
\end{tabular}

Table 3. Inaccuracy values for Psychotria genus followed by the $95 \% \mathrm{CI}$ and then those observed in P. brachyceras. Symbols indicate if the observed values fall above $(\uparrow)$ or below $(\downarrow)$ the $C I$ limits. Differences indicate how many times the observed $P$. brachyceras value is smaller/higher than that of the genus mean. Inaccuracy values are on $\log +1$ scale. They are expressed according to Fig. 3 , wherein raw numbers are displayed.

\begin{tabular}{|c|c|c|c|c|}
\hline & Psychotria genus - mean & Psychotria genus - Cl & Psychotria brachyceras & Difference \\
\hline Stigma inaccuracy - Thrum & 0.92 & $(0.76-1.07)$ & $0.01 \downarrow$ & 91 \\
\hline Stigma inaccuracy - Pin & 0.60 & $(0.50-0.71)$ & $0.01 \downarrow$ & $0.23 \downarrow$ \\
\hline Maladaptive bias - high organs & 0.55 & $(0.37-0.74)$ & 0.56 & -1.39 \\
\hline Anther inaccuracy - Thrum & 0.62 & $(0.51-0.73)$ & $0.84 \uparrow$ & - \\
\hline Anther inaccuracy - Pin & 0.71 & $(0.59-0.83)$ & 1.23 & - \\
\hline Maladaptive bias - low organs & 1.04 & $(0.77-1.31)$ & $0.73 \downarrow$ & 0.75 \\
\hline High organs inaccuracy & 1.29 & $(1.12-1.46)$ & 1.60 & - \\
\hline Low organs inaccuracy & 1.76 & $(1.54-1.98)$ & $1.62 \downarrow$ & 0.28 \\
\hline Total inaccuracy & 2.08 & $(1.88-2.28)$ & & \\
\hline
\end{tabular}

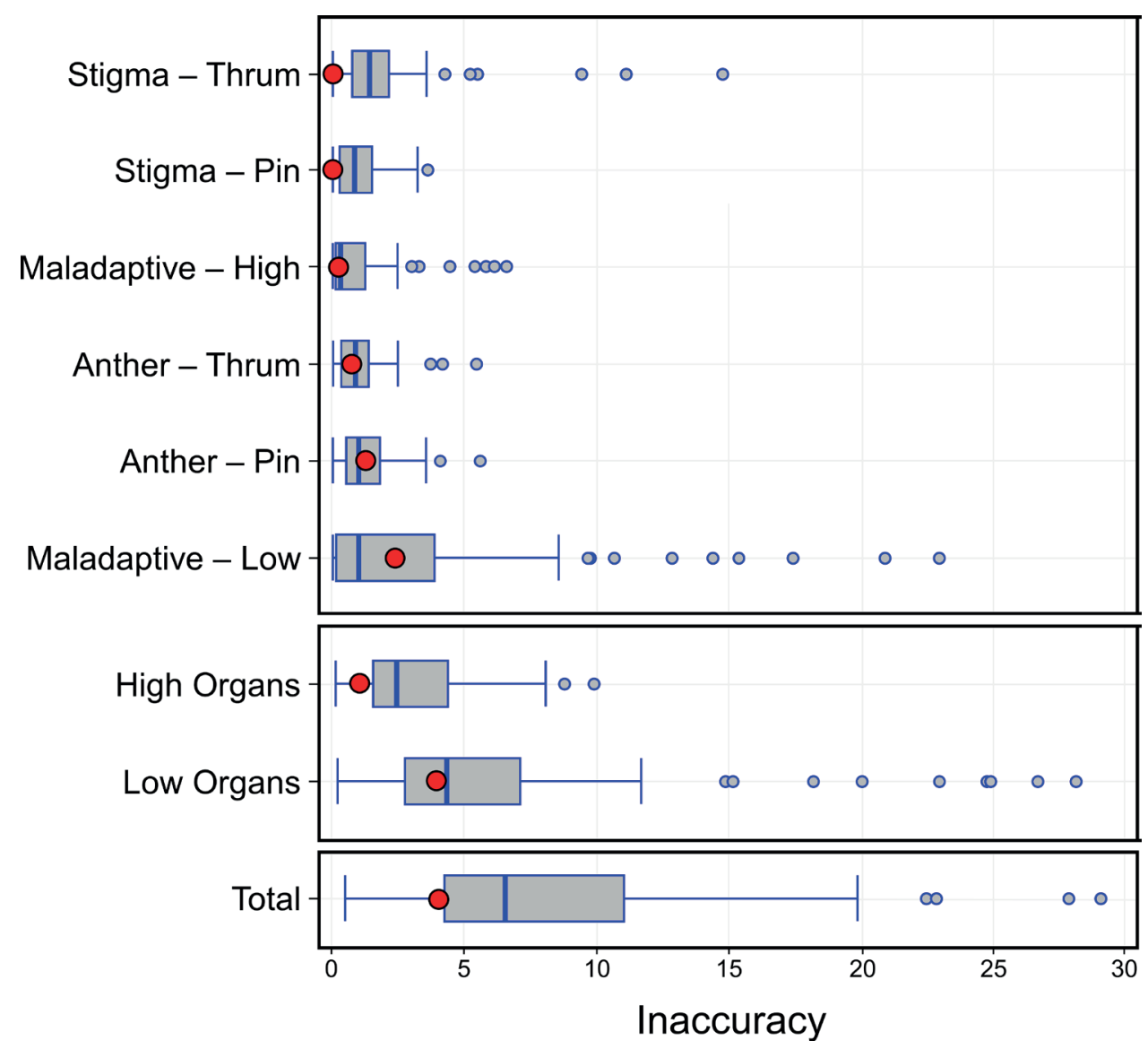

Figure 3. Inaccuracy values of floral organs in Psychotria brachyceras (Rubiaceae). Total inaccuracy, inaccuracy per organ type and maladaptive bias ${ }^{2}$, variance of the anthers and variance of the stigmas of P. brachyceras (red dots; values in ascending order) in relation to those populations of the genus Psychotria (box plots in blue). 
Table 4. Total and per morph fruit set rates (in \%) for the pollination treatments assessing the mating system of Psychotria brachyceras (Rubiaceae). The numbers of treated flowers are expressed within parenthesis. Different letters indicate significant differences in treatment groups.

\begin{tabular}{|c|c|c|c|}
\hline Treatment & Pin & Thrum & \multicolumn{1}{|c|}{ Total } \\
\hline Intermorph cross-pollination & $63.16 \%(19)$ & $81.25 \%(16)$ & $71.43 \%(35)^{\mathrm{b}}$ \\
\hline Intramorph cross-pollination & $0.00 \%(20)$ & $4.00 \%(25)$ & $2.22 \%(45)^{\mathrm{a}}$ \\
\hline Manual self-pollination & $0.00 \%(19)$ & $0.00 \%(16)$ & $0.00 \%(35)^{\mathrm{a}}$ \\
\hline Spontaneous self-pollination & $3.33 \%(30)$ & $5.88 \%(34)$ & $4.69 \%(64)^{\mathrm{a}}$ \\
\hline Agamospermy & $3.33 \%(30)$ & $0.00 \%(28)$ & $1.72 \%(58)^{\mathrm{a}}$ \\
\hline Open pollination & $78.95 \%(38)$ & $71.79 \%(39)$ & $75.32 \%(77)^{\mathrm{b}}$ \\
\hline
\end{tabular}

\section{8 hours}

A

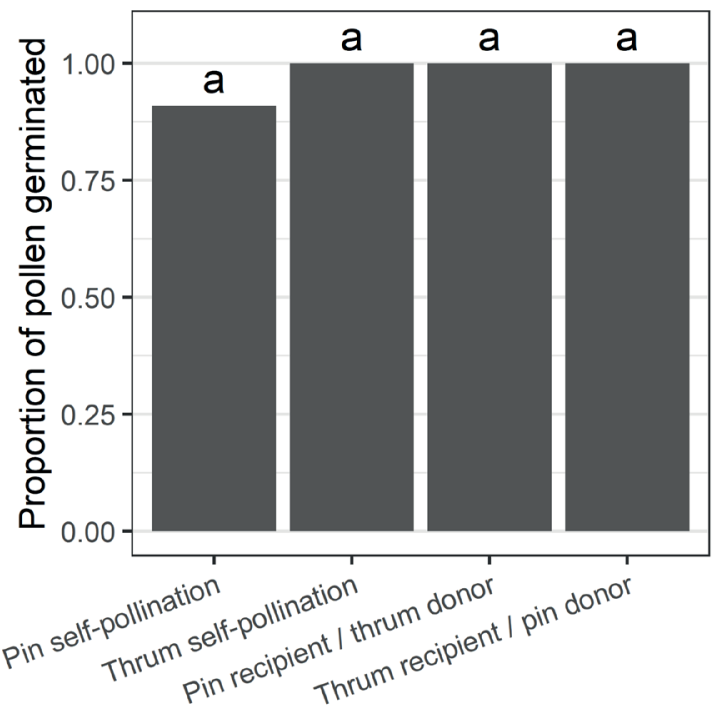

B

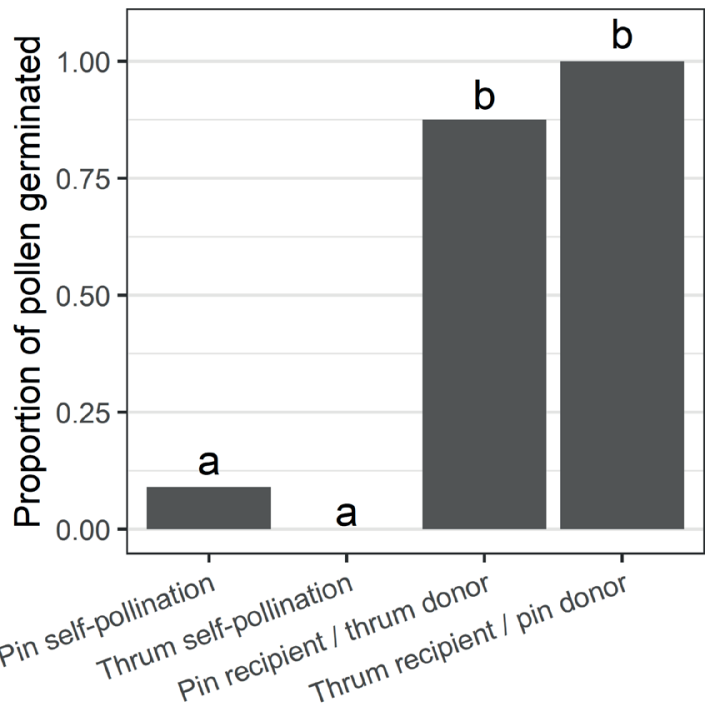

\section{6 hours}
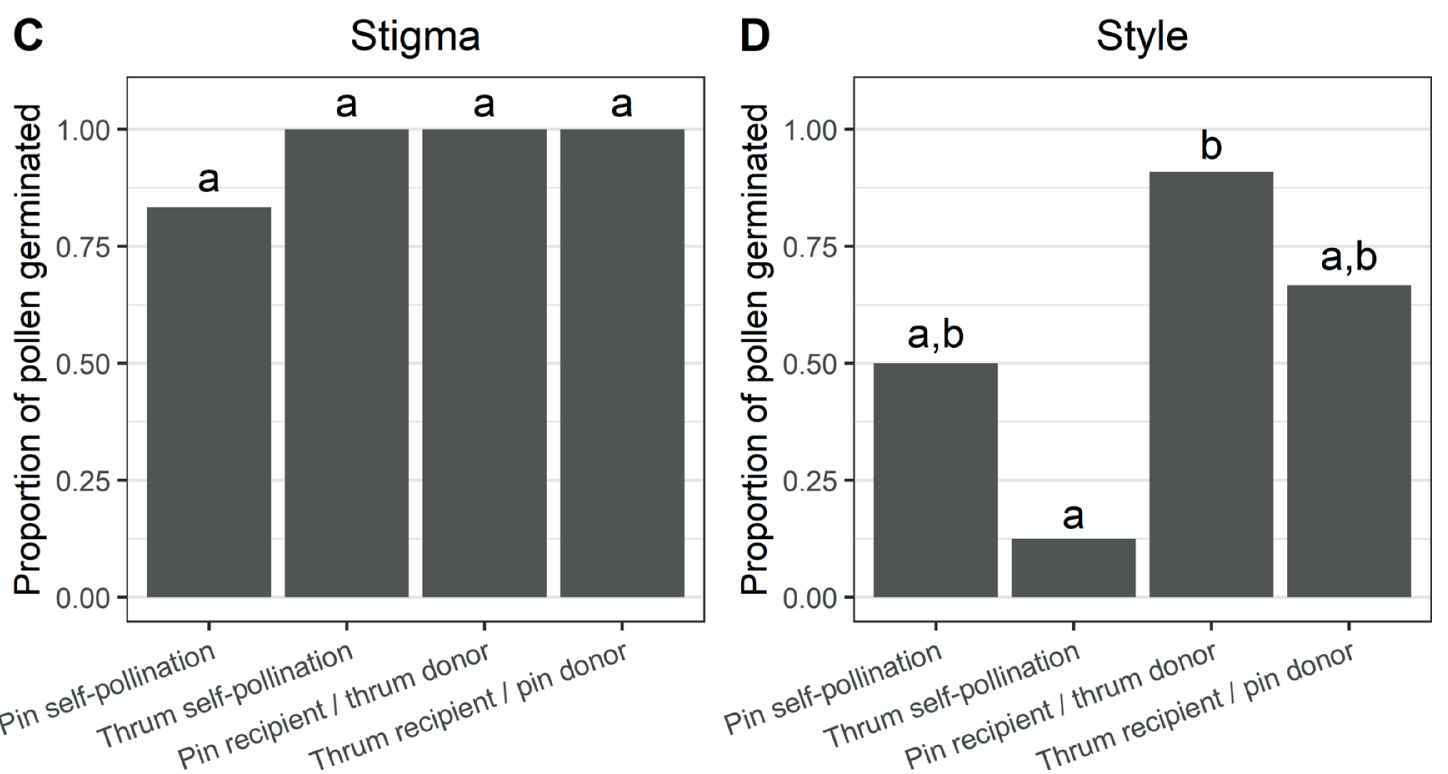

Figure 4. Proportion of pollen tube growth after manual self- and intermorph cross-pollinations in Psychotria brachyceras (Rubiaceae). Proportion of pollen germinated in stigmas $(\mathbf{A}) 8 \mathrm{~h}$ after and $(\mathbf{C}) 16 \mathrm{~h}$ of pollen transfer, and the proportion of pollen tube growth in styles after (B) $8 \mathrm{~h}$ and (D) $16 \mathrm{~h}$ of pollen transfer. Different letters indicate significant differences between treatments at 0.05 level. 

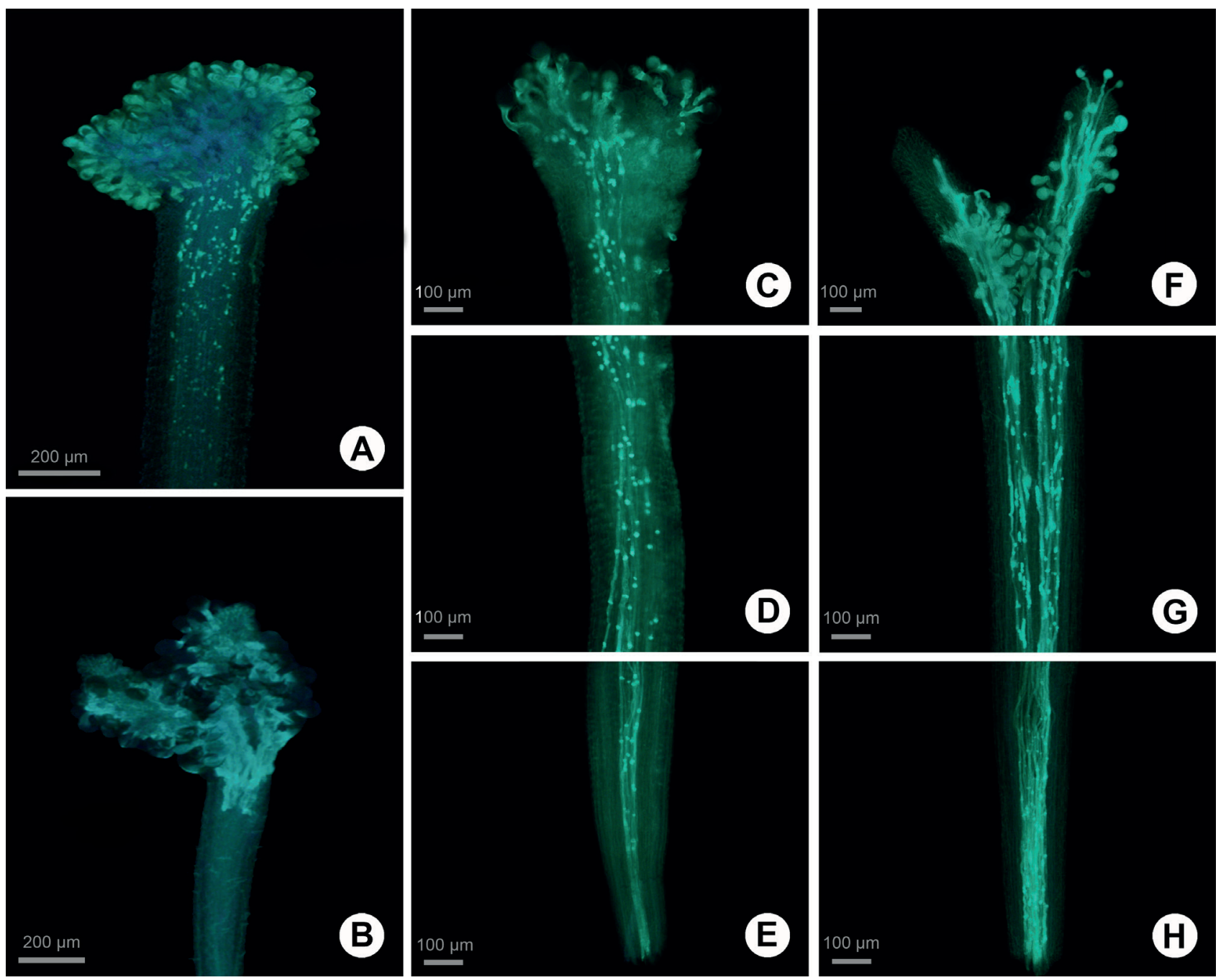

Figure 5. Pollen tube growth after controlled hand pollinations of $P$. brachyceras conducted in the field. Self-pollen germination in (A) pin and (B) thrum stigmas after 16 hours of pollination. Pollen germination and pollen tubes in (C-E) pin and (F-H) thrum pistils after 8 hours of intermorph cross-pollination.

We also found differences at the style level in pistils fixated after $16 \mathrm{~h}$ of pollen transfer $\left(\chi^{2}=12.18 ; \mathrm{df}=3 ; P=0.001\right.$, Fig. 4D). At this time and level, the most distinguishable treatments were the intermorph cross-pollination with pins receiving pollen of thrums (high rate of pollen tube growth) and the thrum self-pollination (low rate of pollen tube growth). The pin self-pollination and the intermorph crosspollination with thrums as recipients showed intermediate proportions of pollen tube growth and no differences from other treatments were detected.

\section{Discussion}

The studied population of P. brachyceras has most typical distyly features similar to other species studied so far. In principle, we did not find associations between the disruption of the distyly system and subtropical distributions. We showed that pin and thrum individuals occurred in similar proportions characterizing an isoplethic population. Stigmas were larger on thrum morphs and there were no differences concerning anther and corolla lengths as well as corolla opening. When looking at reciprocity in sexual organs between morphs, the inaccuracy values were evenly distributed between the two organ types and the maladaptive bias had the smallest values, suggesting reciprocity between thrum and pin morphs. The population had high rates of fruit set in intermorph cross- and open-pollination treatments, negligible fruit set and low pollen tube success after self-pollinations, indicating selfincompatibility and functional distyly, as proposed by Lloyd \& Webb (1992) and Barrett \& Shore (2008).

The pollination treatments and pollen tube growth analysis, together, indicated that the studied population sexually reproduces through intermorph crosses and is self-incompatible, as expected for distylous species. The fact that pollen tube grew down the style even in the manual selfpollination (16 h) suggests that the incompatibility system 
is not operating as tightly as in other typical sporophytic systems, where usually pollen tube arresting occurs early in the stigma (Ganders 1979; Teixeira \& Machado 2004; Barrett \& Shore 2008). Considering the self-pollen tube growth, it seems that incompatibility reactions are stronger within thrum than within pin flowers. This asymmetry is probably needed due to spontaneous selfing likelihood and smaller style length in thrums (Bawa \& Beach 1983). That is, the magnitude of selection to prevent selfing seems to be different in the two morphs. To stop self-pollen tube development, the self-incompatibility reaction needs to occur faster in thrum morphs because pollen tubes have shorter distances (i.e., shorter styles) to travel before reaching the ovary, whereas the reaction can take longer in the long styles of pin morphs (Bawa \& Beach 1983). Overall, pollen tubes from disassortative pollinations (i.e., between different morphs) reached style base within the first $8 \mathrm{~h}$. The same was not true for assortative pollinations (i.e., within the same morph). However, once self-pollen was giving more time to grow ( $16 \mathrm{~h}$ after pollination), we captured a considerable amount of pin self-pollen tubes at the style base. As this species has only two ovules per flower, the advantage of disassortative over assortative crosses probably secure high-quality fertilization even when pollen grains deposited on stigmas are from both morphs (mixed pollination). Our results are similar to other typically congeneric distylous plants, such as Psychotria barbiflora (Teixeira \& Machado 2004), P. suterella (Lopes \& Buzato 2005) and P. poeppigiana (Coelho \& Barbosa 2004). Even though half of the pin self-pollinated pistils had pollen tubes at the styles base, this hardly translated into fruits, which still corroborates with self-incompatibility. Hence, in thrum pistils the site of inhibition is generally in the junction of stigma and style, whereas for pin morphs inhibition occurs from the half portion to the base of the style. This asymmetry in the site of incompatibility reaction between morphs is common in other Rubiaceae species, but equal sites of reaction between morphs is also present in the family (Bawa \& Beach 1983). It is evident that selfincompatibility systems in heterostylous plants display variation in expression (Barrett \& Shore 2008). As more incompatibility mechanisms are identified in Rubiaceae species, more power is giving for future studies to assess the different evolutionary pathways for the evolution of distyly within this family.

Populations with a self-incompatibility system fully operating, usually present pin and thrum morphs in equal proportions (i.e., isoplethy; Ganders 1979), which was the case of this particular population. Because open and intermorph cross-pollination treatments had very high and similar rates of fruit set, it seems that floral morph frequencies are also maintained by high levels of disassortative pollen movements provoked by pollinators (Costa et al. 2017). In distylous species, small differences in the length of the sexual organs can significantly change the rate of disassortative pollination (Barrett 2002; Keller et al. 2014). Hence, to ensure precise pollen transfer by pollinators and the effective functioning of distyly, that is, each morph properly cross-pollinating and fertilizing the other, reciprocal herkogamy is usually accompanied with ancillary characteristics (e.g., corolla length, stigma' and pollen size; (Darwin 1877; Ganders 1979; Lloyd \& Webb 1992; Barrett \& Shore 2008). For P. brachyceras we recorded one of these ancillary features, commonly found in distylous Rubiaceae: larger stigmas in thrum than in pin morphs. This feature has often been reported in distylous populations (e.g., Richards \& Koptur 1993; Castro \& Araujo 2004; Coelho \& Barbosa 2004; Virillo et al. 2007; Watanabe et al. 2015) and may increase the chance of thrum morph pollination. Since stigmas of this morph are positioned below anthers (i.e., reverse herkogamy) its own pollen may also fall in the stigma making self-pollination more likely. Therefore, the larger area may compensate for self-pollen interference and increase the space for picking up pollen from the pin morph (i.e., disassortative pollination; Ree 1997; Barrett 2002). No other ancillary traits were recorded in the population though we did not measure differences in pollen size and pollen production between morphs.

Psychotria brachyceras has high reciprocity, even when compared with the trends of the rest of the genus, which suggests that the subtropical location itself does not interfere with the functionality of distyly. The population presented the inaccuracies evenly distributed between anthers and stigmas of the two organ types (high and low organs). Corolla tube length can influence the reciprocity between morphs because it affects the length of the filaments and by consequence the position of anthers (Faivre \& McDade 2001; Pérez-Barrales et al. 2014). The increase in corolla length seems to reduce stigma and anthers inaccuracies values both in thrum and pin flowers, probably because these floral morphs are adapted to more specialized pollinators (Stang et al. 2006; Yuan et al. 2017). Nevertheless, P. brachyceras presents a relatively small flower and consistently lower inaccuracies values. This suggests that the short corolla tube in this species might select effective pollinators which contact the low and high reproductive structures correctly. The shorter corolla tubes permit high reciprocity which may be a product of constraining the movements of sexual organs within them. This highly precise reciprocity showed by $P$. brachyceras is one more factor that helps to explain the success of natural (open) pollination in the studied population.

The use of continuous variation of inaccuracy values allowed us to investigate whether P. brachyceras has similar patterns of distyly traits compared to the rest of the genus. In this sense, based on our study case we can confirm that this particular population has experienced no changes in terms of distyly features when compared to other populations of other species of Psychotria. This is probably due to the presence of an efficient incompatibility 
system that prevents self-fertilization and a suitable set of efficient pollinators in the area. Psychotria brachyceras occurs along the tropic-subtropic gradient in Brazil (Taylor 1996). Thus, this species is a suitable system to evaluate whether populations along this gradient show variations in distyly providing insights to what specifically changes in ecological factors may influence its functioning. We encourage further studies, by including more species and more populations, to investigate in which extent geography determines deviations of the polymorphism or if they are mostly associated with other factors related to decreases in pollinator availability and population density (e.g., Sakai \& Wright 2008).

\section{Conclusion}

Here we evaluated the distyly features of one southern subtropical population of $P$. brachyceras showing the reciprocal arrangement between thrum and pin floral morphs and the different modes of the self-incompatibility operation between the two morphs, which effectively prevent selfing. Moreover, P. brachyceras shows higher reciprocity than the general trend observed for the genus, which under the current conditions of mates and pollinator availability guarantee reproductive success and the maintenance of distyly in the population.

\section{Acknowledgements}

We thank Vinícius L. G. Brito for fruitful discussions that improved the quality of the manuscript and Edison Zefa, who kindly allowed us to use the stereomicroscope in Universidade de Pelotas.

\section{References}

Abdi H, Williams LJ. 2010. Principal component analysis. Wiley interdisciplinary reviews: computational statistics 2: 433-459.

Alvares CA, Stape JL, Sentelhas PC, Moraes G, Leonardo J, Sparovek G. 2013. Köppen's climate classification map for Brazil. Meteorologische Zeitschrift 22: 711-728.

Armbruster WS, Bolstad GH, Hansen TF, Keller B, Conti E, Pélabon C. 2017. The measure and mismeasure of reciprocity in heterostylous flowers. New Phytologist 215: 906-917.

Bawa KS, Beach JH. 1983. Self-incompatibility systems in the Rubiaceae of a tropical lowland wet forest. American Journal of Botany 70: 1281-1288.

Barrett SCH. 2019. 'A most complex marriage arrangement': recent advances on heterostyly and unresolved questions. New Phytologist 224: 1051-1067.

Barrett SCH, Shore JS. 2008. New insights on heterostyly: comparative biology, ecology and genetics. In: Franklin-Tong VE. (ed.) Selfincompatibility in flowering plants. Berlin, Springer-Verlag. p. 3-32.

Barrett SCH. 2002. The evolution of plant sexual diversity. Nature Reviews Genetics 3: 274-284.

Bates D, Maechler M, Bolker B, et al. 2018. lme4: Linear mixed-effects models using Eigen and S4. R package version 1.1-18-1. https:// cran.r-project.org/package=lme4. 12 Sep. 2019.

Brys R, Jacquemyn H. 2019. The impact of individual inaccuracy of reciprocal herkogamy on legitimate pollen deposition and seed set in a distylous self-incompatible herb. Journal of Ecology 108: 1-13.
Cabin RJ, Mitchell RJ. 2000. To bonferroni or not to bonferroni: when and how are the questions. Bulletin of the Ecological Society of America 81: 246-248.

Cardoso JCF, Viana ML, Matias R, et al. 2018. Towards a unified terminology for angiosperm reproductive systems. Acta Botanica Brasilica 32: 329-348.

Castro CC, Araujo AC. 2004. Distyly and sequential pollinators of Psychotria nuda (Rubiaceae) in the Atlantic rain forest, Brazil. Plant Systematics and Evolution 244: 131-139.

Coelho CP, Barbosa AAA. 2004. Biologia reprodutiva de Psychotria poeppigiana Mull. Arg. (Rubiaceae) em mata de galeria. Acta Botanica Brasilica 18: 481-489.

Consolaro H, Silva SC, Oliveira PE. 2011. Breakdown of distyly and pinmonomorphism in Psychotria carthagenensis Jacq.(Rubiaceae). Plant Species Biology 26: 24-32.

Costa J, Castro S, Loureiro J, Barrett SCH. 2017. Experimental insights on the function of ancillary pollen and stigma polymorphisms in plants with heteromorphic incompatibility. Evolution 71: 121-134.

Dafni A. 1992. Pollination ecology: a practical approach. Oxford University Press, Oxford.

Darwin CR. 1877. The different forms of flowers on plants of the same species. London, John Murray.

Davis AP, Govaerts R, Bridson DM, Ruhsam M, Moat J, Brummitt NA. 2009. A Global Assessment of Distribution, Diversity, Endemism, and Taxonomic Effort in the Rubiaceae. Annals of the Missouri Botanical Garden 96: 68-79.

Dulberger R. 1992. Floral polymorphisms and their functional significance in the heterostylous syndrome. In: Barrett SCH. (ed.) Evolution and function of heterostyly. Berlin, Springer Verlag. p. 41-84

Faivre AE, McDade LA. 2001. Population-level variation in the expression of heterostyly in three species of Rubiaceae: does reciprocal placement of anthers and stigmas characterize heterostyly?. American Journal of Botany 88: 841-853.

Ferrero V, Rojas D, Vale A, Navarro L. 2012. Delving into the loss of heterostyly in Rubiaceae: Is there a similar trend in tropical and nontropical climate zones?. Perspectives in Plant Ecology, Evolution and Systematics 14: 161-167.

Ganders FR. 1979. The biology of heterostyly. New Zealand Journal of Botany 17: 607-635.

Hope RM. 2013. Rmisc: Ryan Miscellaneous. R package version 1.5. https:// CRAN.R-project.org/package=Rmisc. 12 Sep. 2019.

Husson F, Josse J, Le S, Mazet J. 2018. FactoMineR: Multivariate Exploratory Data Analysis and Data Mining. R package version 1.41. https://CRAN.R-project.org/package=FactoMineR.12 Sep. 2019.

Jaeger B. 2017. R2glmm: Computes R squared for mixed (multilevel) models (LMMs and GLMMs). R package version 0.1.2. https://CRAN.R-project. org/package=r2glmm. 12 Sep. 2019.

Jiang XF, Zhu XF, Chen LL, Li QJ. 2018. What ecological factors favor the shift from distyly to homostyly? A study from the perspective of reproductive assurance. Journal of Plant Ecology 11: 645-655.

Johansen DA. 1940. Plant microtechnique. London, McGraw-Hill Book Company.

Keller B, Thomson JD, Conti E. 2014. Heterostyly promotes disassortative pollination and reduces sexual interference in Darwin's primroses: evidence from experimental studies. Functional Ecology 28: 1413-1425.

Kuznetsova A, Brockhoff PB, Christensen RHB. 2018. lmerTest: Tests in Linear Mixed Effects Models. R package version 3.0-0. https:// cran.r-project.org/package=lmerTest. 12 Sep. 2019.

Lloyd DG, Webb CJ. 1992. The evolution of heterostyly. In: Barrett SC. (ed.) Evolution and function of heterostyly. Berlin, Springer Verlag. p. 151-178.

Lopes LE, Buzato S. 2005. Biologia reprodutiva de Psychotria suterella Muell. Arg. (Rubiaceae) e a abordagem de escalas ecológicas para a fenologia de floração e frutificação. Revista Brasileira de Botânica 28: 785-795.

Mangiafico S. 2020. rcompanion: Functions to Support Extension Education Program Evaluation. R package version 2.3.26. https:// CRAN.R-project.org/package=rcompanion. 04 Jan. 2021.

Martin FW. 1959. Staining and observing pollen tubes in the style by means of fluorescence. Stain Technology 34: 125-128. 
Matias R, Oliveira ASD, Furtado MT, et al. 2016. Sistema reprodutivo atípico de duas espécies de Rubiaceae: distilia com autoincompatibilidade parcial no morfo brevistilo? Rodriguésia 67: 357-368.

McArdle BH, Anderson MJ. 2001. Fitting multivariate models to community data: a comment on distance-based redundancy analysis. Ecology 82: 290-297.

Naiki A. 2012. Heterostyly and the possibility of its breakdown by polyploidization. Plant Species Biology 27: 3-29.

Nakagawa S, Schielzeth H. 2013. A general and simple method for obtaining R2 from generalized linear mixed-effects models. Methods in Ecology and Evolution 4: 133-142.

Oksanen J, Blanchet FG, Kindt R, et al. 2018. vegan: Community Ecology Package. R package version 2.5-1. https://CRAN.R-project.org/ package=vegan. 12 Sep. 2019.

Pérez-Barrales R, Simón-Porcar VI, Santos-Gally R, Arroyo J. 2014. Phenotypic integration in style dimorphic daffodils (Narcissus, Amaryllidaceae) with different pollinators. Philosophical transactions of the Royal Society of London. Series B, Biological Sciences 369: 20130258. doi: 10.1098/rstb.2013.0258

R Development Core Team. 2019. R: A language and environment for statistical computing. R Foundation for Statistical Computing, Vienna, Austria. https://www.Rproject.org/. 12 Set. 2019.

Ree RH. 1997. Pollen Flow, Fecundity, and the Adaptive Significance of Heterostyly in Palicourea padifolia (Rubiaceae). Biotropica 29: 298-308.

Richards JH, Koptur S. 1993. Floral variation and distyly in Guettarda scabra (Rubiaceae). American Journal of Botany 80: 31-40.

Rodrigues EB, Consolaro H. (2013). Atypical distyly in Psychotria goyazensis Mull. Arg.(Rubiaceae), an intramorph self-compatible species. Acta Botanica Brasilica 27: 155-161.

Sá T, Furtado MT, Ferrero V, et al. 2016. Floral biology, reciprocal herkogamy and breeding system in four Psychotria species (Rubiaceae) in Brazil. Botanical Journal of the Linnean Society 182: 689-707.

Sakai S, Wright SJ. 2008. Reproductive ecology of 21 coexisting Psychotria species (Rubiaceae): when is heterostyly lost?. Biological Journal of the Linnean Society 93: 125-134.

Stang M, Klinkhamer PG, Van Der Meijden E. 2006. Size constraints and flower abundance determine the number of interactions in a plant-flower visitor web. Oikos 112: 111-121.
Taylor CM. 1996. Overview of Psychotrieae (Rubiaceae) in the neotropics. Opera Botanica Belgica 7: 261-270.

Teixeira LAG, Machado IC. 2004. Biologia da polinização e sistema reprodutivo de Psychotria barbiflora DC. (Rubiaceae). Acta Botanica Brasilica 18: 853-862.

Trevizan R, Cardoso JCF, Coelho CP, Consolaro H, Furtado MT, Oliveira PE. 2021. Inaccuracy patterns and precise pollination among distylous Palicourea and Psychotria (Rubiaceae). Perspectives in Plant Ecology, Evolution and Systematics 53: 125645. doi: 10.1016/j. ppees.2021.125645

Venables WN, Ripley BD. 2002. Modern Applied Statistics with S. 4th edn. New York, Springer.

Virillo BC, Ramos NF, Castro CC, Semir J. 2007. Floral biology and breeding system of Psychotria tenuinervis Muell. Arg. (Rubiaceae) in the Atlantic rain forest, SE Brazil. Acta Botanica Brasilica 21: 879-884.

Watanabe K, Shimizu A, Sugawara T. 2013. Dioecy derived from distyly and pollination in Psychotria rubra (Rubiaceae) occurring in the Ryukyu Islands, Japan. Plant species biology 29: 181-191.

Watanabe K, Kato H, Sugawara T. 2014. Distyly and incompatibility in Psychotria homalosperma (Rubiaceae), an endemic plant of the oceanic Bonin (Ogasawara) Islands. Flora-Morphology, Distribution, Functional Ecology of Plants 209: 641-648.

Watanabe K, Yang TA, Nishihara C, et al. 2015. Distyly and floral morphology of Psychotria cephalophora (Rubiaceae) on the oceanic Lanyu (Orchid) Island, Taiwan. Botanical Studies 56: 1-9.

Yuan S, Barrett SC, Duan T, Qian X, Shi M, Zhang D. 2017. Ecological correlates and genetic consequences of evolutionary transitions from distyly to homostyly. Annals of Botany 120: 775-789.

Zhou W, Barrett SCH, Li HD, et al. 2017. Phylogeographic insights on the evolutionary breakdown of heterostyly. New Phytologist 214: 1368-138.

Zhou W, Barrett SC, Wang H, Li DZ. 2015. Reciprocal herkogamy promotes disassortative mating in a distylous species with intramorph compatibility. New Phytologist 206: 1503-1512.

Zuur AF, Ieno EN, Elphick CS. 2010. A protocol for data exploration to avoid common statistical problems. Methods in Ecology and Evolution 1: 3-14.

Zuur A, Ieno EN, Walker N, Saveliev AA, Smith GM. 2009. Mixed effects models and extensions in ecology with R. New York, Springer. 